\title{
PROCESSOS FORMATIVOS NA EDUCAÇÃO PROFISSIONAL: REFLEXÕES SOBRE O PROGRAMA MULHERES MIL DO IFSULDEMINAS ${ }^{1}$
}

\author{
Cleonice Maria da Silva \\ cleonicesilva0825@gmail.com \\ Instituto Federal de Educação, Ciência e Tecnologia do Sul de Minas Gerais
}

RESUMO: O presente trabalho tem por objetivo apresentar os resultados de uma investigação em que se buscou discutir o Programa Mulheres Mil, desenvolvido pelo IFSULDEMINAS na cidade de Inconfidentes. A pesquisa foi realizada sob a forma de um estudo de caso e os dados foram coletados a partir de entrevistas semiestruturadas com educadoras/es que atuaram no programa nos anos de 2012 e 2013 e foram discutidos com base nas teorizações pós-estruturalistas e dos estudos culturais. O estudo demonstra que o Programa Mulheres Mil não consegue romper com problemas históricos relacionados à questão de gênero, mas avança em relação a uma estratégia metodológica capaz de sensibilizar as mulheres quanto à possibilidade de mudança de suas trajetórias de vida.

PALAVRAS-CHAVE: programas educativos; gênero; qualificação profissional.

\section{FORMATION PROCESSES IN VOCATIONAL EDUCATION: \\ REFLECTIONS ABOUT THE THOUSAND WOMEN PROGRAM BY THE IFSULDEMINAS}

ABSTRACT: The following essay aims to present the results of an investigation in which the Thousand Women Program, developed by IFSULDEMINAS in the city of Inconfidentes, is discussed. The research was fulfilled as a case study, and data was collected through semi structured interviews with educators who have worked in the program in 2012 and 2013. The data was discussed based on poststructuralist theorizations and cultural studies. The study shows that the Thousand Women Program is not able to disrupt historical problems related to the matter of gender, but it progresses in relation to a methodological strategy capable of sensitizing women regarding the possibility of change of their life trajectories.

KEYWORDS: educational programs; gender; professional qualification.

\footnotetext{
${ }^{1}$ Artigo decorrente de pesquisa desenvolvida sob orientação do Prof. Dr. Fábio Pinto Gonçalves dos Reis no Programa de Pós-Graduação em Educação da Universidade Federal de Lavras com o título Formação de trabalhadoras: o programa Mulheres Mil sob o olhar de suas educadoras.
} 


\section{Introdução}

Os Institutos Federais de Educação, Ciência e Tecnologia (IF) foram criados em 2008 com a missão de promover a justiça social, a equidade e o desenvolvimento sustentável, com a expectativa de responder à demanda por formação profissional, difusão de conhecimentos científicos e suporte aos arranjos produtivos locais (PACHECO, 2012).

A expansão dessas instituições coloca em cena outros atores sociais ao ampliar a diversidade sociocultural dos sujeitos aos quais atende e se credenciam como parceiras locais no desenvolvimento de ações que possam concorrer para a redução das desigualdades. Deste modo, os Institutos Federais passam a ter uma função estratégica na composição e estabelecimento de programas que tenham como foco a qualificação/formação dos trabalhadores.

De acordo com Pacheco (2012), a implantação dos IF está relacionada ao conjunto de políticas para a educação profissional e tecnológica, pela cooperação com estados e municípios na oferta de cursos técnicos, bem como pela defesa de que os processos de formação para o trabalho estejam vinculados à elevação de escolaridade. Pode-se acrescentar que

\footnotetext{
Integrados à política de ordenamento da Rede Federal de Educação Profissional, Científica e Tecnológica, vinculada ao Ministério da Educação, os Institutos foram, no seu nascedouro, convocados a realizar a interiorização da oferta educacional a partir das cidades-polo; a cobertura do maior número possível de mesorregiões e a sintonia com os arranjos produtivos, sociais e culturais locais (MACHADO, 2011, p. 355).
}

Entendo que o fato de os IF possuírem criação recente e, portanto, de haver pouca produção sobre as atividades que desenvolvem, nos diferentes territórios brasileiros, torna-os um espaço profícuo para pesquisas sobre as ações que realizam. Ademais, nos últimos anos, essas instituições têm realizado uma série de projetos e programas do governo federal que, não raro, são extintos, fundem-se a outros e/ou são instituídos novos, desconsiderando a experiência dos projetos/programas pré-existentes, o que sinaliza para a importância de se promover esta reflexão.

Discuto neste artigo o Programa Mulheres Mil, criado pelo governo federal e desenvolvido, no país, pelos Institutos Federais. Por se tratar de uma ação governamental que coloca em confluência políticas públicas de variadas áreas, o estudo do Programa Mulheres Mil no Brasil tem se apresentado como uma área investigativa interdisciplinar, 
Processos formativos na educação profissional: reflexões sobre o programa Mulheres Mil do IFSULDEMINAS

cuja discussão contempla diferentes perspectivas teórico-metodológicas, contextos histórico-sociais e culturais. Uma consulta ao Banco de Teses da Coordenação de Aperfeiçoamento de Pessoal de Nível Superior e à Biblioteca Brasileira de Teses e Dissertações apresentou como resultado os trabalhos de BRAGA (2011), que discute o programa no contexto do Instituto Federal do Tocantins; OLIVEIRA (2013), no Instituto Federal de Sergipe; RIBEIRO (2013), no Instituto Federal de Goiás; LAGOS (2014), no Instituto Federal do Paraná - em comunidade Quilombola; e PEREIRA (2015) no Instituto Federal de Santa Catarina.

Importa-me, neste artigo, fazer uma reflexão sobre o contexto em que o programa foi desenvolvido, aquele em que os chamados atores/agentes, cuja ação, às vezes negligenciada no âmbito da elaboração das políticas públicas, têm o desafio de reinventar e reinterpretar uma política que foi formatada para todos os recantos do país.

Embora o Mulheres Mil tenha sido elaborado como um programa nacional, para ser desenvolvido nos Institutos Federais de todos os estados brasileiros ${ }^{2}$, os diferentes atores sociais têm a possibilidade de (re)interpretá-lo, (re)adequá-lo e (re)criá-lo no âmbito de suas comunidades, ou seja, existem arranjos locais decorrentes da execução do programa que merecem ser estudados.

A instituição selecionada para o trabalho de pesquisa, quase centenária, na condição de Escola Agrotécnica Federal, atendia a um público diferente do proposto pelo Mulheres Mil, o que faz com que o registro do relato destes/as educadores/as seja importante, principalmente por se tratar de uma experiência nova.

O material empírico da pesquisa foi produzido em um trabalho de campo baseado no estudo dos documentos oficiais: Mulheres Mil na rede federal: caminhos da inclusão ${ }^{3}$ (ROSA, 2011a); Guia Metodológico do sistema de acesso, permanência e êxito (MEC, 2011c); Mulheres Mil: do sonho à realidade 4 (ROSA, 2011b); Chamada pública MEC/SETEC de $n^{\circ}$ 1/2011 e 1/2012. Estes documentos encontram-se disponibilizados pela coordenação local do Programa Mulheres Mil, bem como o projeto pedagógico dos cursos, os relatórios anuais e os formulários de cadastro das mulheres.

2 O Brasil possui 38 Institutos Federais e 562 Campi vinculados. Fonte: Brasil (2014).

3 Relato da parceria Brasil-Canadá para desenvolvimento do Programa Mulheres Mil nas regiões norte e nordeste. Disponível em: <http://mulheresmil.mec.gov.br/central-de-entrevistas/1679-mulheres-milna-rede-federal-caminhos-da-inclusao >. Acesso em: 11 jan. 2014.

4 Documento-base do Programa Mulheres Mil e pelo qual são desenvolvidas todas as suas ações. Disponível em: <http://mulheresmil.mec.gov.br/central-de-entrevistas/1676-mulheres-mil-do-sonho-arealidade>. Acesso em: 10 jan. 2014. 


\section{Mulheres Mil: contexto de surgimento e expansão}

O Projeto Mulheres Mil: educação, cidadania e desenvolvimento sustentável resulta de um conjunto de ações econômicas, políticas, sociais e de decisões que refletem tensões, conflitos e acordos decorrentes de uma parceria entre Brasil e Canadá. Discutirei o programa com base nos documentos Mulheres Mil na rede federal: caminhos de inclusão (ROSA, 2011a); Guia Metodológico do Programa Nacional Mulheres Mil: educação, cidadania e desenvolvimento sustentável (MEC, 2008); e Mulheres Mil: do sonho à realidade (ROSA, 2011b), que possibilitam a compreensão do seu surgimento.

A ideia do Mulheres Mil começou no verão de 2005. Fizemos um projeto piloto que foi um sucesso e decidimos fazer um projeto mais longo, tanto para o Brasil quanto para o Canadá. Então, ao final de um projeto em turismo, em Natal, averiguamos se havia interesse das pessoas de participar de um projeto de um ano sobre Avaliação e Reconhecimento da Aprendizagem Prévia $\operatorname{ARAP}^{5}$ (ROSA, 2011a, p. 15).

Porque houve necessidade de articular a proposta a uma agência financiadora, buscou-se parceria junto à Agência Canadense para o Desenvolvimento Internacional $\mathrm{CIDA}^{6}$.

Começamos a negociar com a CIDA, que inicialmente pretendia realizá-lo somente na Região Nordeste, mas comprovamos com dados estatísticos que o Norte $^{7}$ também era uma região desfavorecida do nosso país e que merecia atenção. Então, eles concordaram e conseguimos montar o Mulheres Mil com os primeiros 13 subprojetos. E assim ele começou (ROSA, 2011a, p. 7).

Para viabilizar o processo de desenvolvimento do projeto, foram constituídas parcerias com os Centros Federais de Educação Tecnológica (CEFET), com a Associação dos Colleges Comunitários Canadenses (ACCC) e com a Agência Canadense para o Desenvolvimento Internacional (CIDA). Conforme registros, o motivo para a escolha das regiões norte e nordeste foram os índices de exclusão.

5 A metodologia Avaliação e Reconhecimento de Aprendizagem Prévia (ARAP) foi um mecanismo desenvolvido pelos Community Colleges do Canadá para promoção do acesso de pessoas desfavorecidas. Este mecanismo foi adaptado para atender às especificidades das mulheres brasileiras. Fonte: Rosa (2011a).

6 Fundo canadense que financia organizações não governamentais na área de direitos humanos e prevenção da violência sexual. Prioriza projetos cujo enfoque seja a juventude, as crianças e as mulheres.

7 Os estados participantes da região norte e nordeste foram Alagoas, Bahia, Maranhão, Paraíba, Piauí, Roraima, Tocantins, Amazonas, Ceará, Pará, Pernambuco, Rio Grande do Norte e Sergipe.

Olh@res, Guarulhos, v. 4, n. 1, p. 161-181, maio 2016. 
O Mulheres Mil começou como um projeto voltado para as mulheres do Norte e Nordeste, porque nessas regiões se localizam os maiores índices de exclusão social em nosso país, e também porque naquele momento não tinha como estendê-lo a todo o território nacional ${ }^{8}$. Portanto, a partir do conhecimento adquirido nessa primeira experiência, nosso desejo, nossa intenção e nossa firme determinação é que o Projeto Mulheres Mil seja estendido para todo o território nacional para que se transforme não somente em um programa, mas em uma política da SETEC, da Educação Profissional e Tecnológica brasileira. Trabalhar com as mulheres em situação de risco social é uma das prioridades que nos orientam na Secretaria, portanto, a meta é que o Projeto Mulheres Mil deixe de ser um projeto para ser uma política de inclusão e emancipação das mulheres, capitaneada pela SETEC (ROSA, 2011a, p. 5 - grifo meu).

O Programa Mulheres Mil foi elaborado como política pública nacional, em 2011, incorporado às ações do Programa Brasil sem Miséria, o qual reforça a necessidade de vinculá-lo a regiões de baixo Índice de Desenvolvimento Humano e às populações integrantes do Programa Territórios da Cidadania ${ }^{9}$.

Delineia-se um programa que articula ações interministeriais, tendo, então: a Secretaria de Educação Profissional e Tecnológica como coordenadora do programa e, como parceiras, as Secretarias de Política para Mulheres e a de Direitos Humanos; a Organização dos Estados Ibero-americanos; o Ministério de Desenvolvimento Social e Combate à Fome; e o Conselho Nacional das Instituições da Rede Federal de Educação Profissional, Científica e Tecnológica.

Estender o programa para todo território brasileiro parece ter se tornado possível, em 2011, depois de os Institutos Federais passarem pelo processo de expansão, com aumento da destinação de recursos, criação de novos campi e contratação de pessoal. A ampliação da Rede tornou viável articular ações de intervenção, em nível local. No seu eixo estruturante, os IF incorporam o papel de promotores de processos inclusivos e de desenvolvimento local.

Ao assumir o papel de incubadoras de políticas públicas afirmativas, inclusivas e de equidade e ao compreender que seu verdadeiro endereço é o território onde estão inseridos, os nossos Institutos demonstram a compreensão de seu espaço e responsabilidades com o projeto de nação em curso no nosso país (ROSA, 2011a, p. 10 - grifo meu).

8 Os Institutos Federais foram legalmente criados em 2008, portanto, não havia no momento mencionado uma Rede formalmente constituída que pudesse levar a cabo o desenvolvimento do Programa. Além disso, existe a questão da focalização dos recursos, pois o parceiro externo financia projetos que tenham como foco segmentos, populações e regiões específicas do mundo.

9 Programa que tem por objetivos promover o desenvolvimento econômico e universalizar programas básicos de cidadania por meio de uma estratégia de desenvolvimento territorial sustentável, articula ações do Governo Federal, estados e municípios. A região sul do estado de Minas Gerais não se enquadra nos critérios de oferta do programa. 
Além disso, os IF figuram nos textos como um observatório de políticas públicas e do universo social, econômico, geográfico, educacional, cultural, científico e tecnológico do seu entorno (MEC, 2011c).

Incorporar o Programa Mulheres Mil às ações do Programa Brasil sem Miséria e priorizar as mulheres usuárias de suas propostas para as atividades formativas da educação profissional foi uma estratégia para tentar possibilitar que elas não dependessem unicamente da transferência de renda e, ao mesmo tempo, constituiu-se em uma forma de intervir na família.

A ampliação do programa em escala nacional implica considerar, contudo, outras questões. No documento base do projeto piloto, por exemplo, há menção de que o Norte e o Nordeste foram escolhidos para iniciar o programa, porque a condição das mulheres daquelas regiões, ao se considerarem as estatísticas de alfabetização e empregabilidade, constituíam as piores do país. Assim, há que se pensar que, nas demais regiões brasileiras, as adversidades existem, mas não com a mesma dimensão dos estados mencionados.

A opção pelo recorte de gênero foi explicada pelo caráter multiplicador que a mulher assume diante de sua família e de sua comunidade. Por ocasião da implementação do projeto piloto, conforme documento do programa, constatou-se que as mulheres formadas passaram a contribuir com a permanência dos filhos na escola, auxiliando-os e estimulando-os a aprofundar seus estudos. Além disso, considerou-se relevante o fato de que as educandas socializavam o conhecimento adquirido com outras mulheres da comunidade, convocando-as a também participar da proposta.

Elaborado e vinculado à pasta do Ministério da Educação, o Mulheres Mil propõese a contribuir para o alcance da educação de jovens e adultos, com o objetivo de elevar a escolaridade de suas educandas. Ademais, ao aliar a educação regular com a formação profissional, procura reduzir o índice médio de evasão por considerar que, neste caso, a aluna vê no programa uma possibilidade de ingresso no mundo do trabalho.

Baseado na avaliação dos dados do programa desenvolvido nas regiões Norte e Nordeste, foi verificado, como consequência dessa ação, de acordo com a Chamada Pública do MEC, que as alunas têm diversas alternativas de ingressar no mercado de trabalho, seja por meio de iniciativas empreendedoras próprias, seja mediante a formação de cooperativas, associações, trabalhos com economia solidária ou mesmo por meio de empregos formais em empresas ${ }^{10}$.

\footnotetext{
${ }^{10}$ Chamada Pública MEC/SETEC - 01/2011
} 
O Mulheres Mil tem por objetivos:

\begin{abstract}
ser instrumento de diálogo com a comunidade, permitindo o ingresso da população feminina em situação de vulnerabilidade social nas instituições de educação profissional e tecnológica; reconhecer a aprendizagem prévia das mulheres, respeitando sua trajetória de vida e sua construção social; contribuir com o desenvolvimento da competência institucional na aplicação de metodologias, instrumentos e currículos que materializem os processos de inclusão e permanência das mulheres no sistema educacional e no mundo do trabalho; fomentar a equidade de gênero, a emancipação e o empoderamento das mulheres por meio do acesso à educação e ao mundo do trabalho; estabelecer diálogos e parcerias com o mundo do trabalho para possibilitar o ingresso e a permanência das educandas nos seus empregos e empreendimento (MEC, 2011c, p. 5).
\end{abstract}

Muito embora o programa apresente como objetivo principal a ampliação da escolaridade das mulheres, essa estratégia pode ser capaz de desencadear uma série de outros efeitos "intencionais", por exemplo, no que concerne a comportamentos relativos à saúde, qualidade de vida e que não se reduzem apenas às mulheres que passaram pelo processo formativo, incluindo também suas respectivas famílias.

Essas questões trouxeram à tona a necessidade de se pensar o currículo formativo prescrito nacionalmente. De acordo com o Guia Metodológico do Programa Nacional Mulheres Mil (MEC, 2011c), o projeto pedagógico do programa deve contemplar um Módulo Central, obrigatório em todas as instituições, com temáticas que articulem políticas de outras áreas e envolvam a aprendizagem sobre a realidade.

\title{
Proposta formativa, currículo e práticas educativas
}

$\mathrm{Na}$ apresentação do projeto pedagógico do curso de formação do IFSULDEMINAS são expostos os dados que justificariam sua oferta, como: o percentual de famílias chefiadas por mulheres; a invisibilidade das condições sociais das mulheres decorrentes dos cuidados com a família; e a existência de mulheres cujas atividades laborais estão vinculadas a trabalhos com baixa proteção social.

Em seguida, apresentam-se as finalidades da formação. A proposta de trabalho é o empoderamento dessas mulheres, uma possibilidade de torná-las gestoras de suas próprias histórias. A título de contexto local, o projeto pedagógico estabelece que o critério adotado na seleção das mulheres não será apenas a renda.

Apesar do diagnóstico realizado para elaboração do projeto pedagógico do curso e da demanda para área de serviços, a inserção produtiva das mulheres apresenta-se como 
um desafio para os gestores do programa, uma vez que existem especificidades em cada município no qual ele é desenvolvido.

A proposta formativa está alicerçada na ideia de certificação de aprendizagens formais e não formais e no reconhecimento dos saberes que as mulheres desenvolvem ao longo da vida. O Guia Metodológico, como prescrição curricular das atividades a ser desenvolvidas, evoca a experiência de vida das mulheres como estratégia de aproximação e estabelecimento de vínculos afetivos que possibilitem romper com ruídos e tensões que possam dificultar as aprendizagens. O trabalho tem a qualidade de não se pretender único: seus elaboradores entendem que, baseados na expansão do Mulheres Mil pelo país e na utilização de sua metodologia pelos IF, em outros contextos, "novas experiências permitirão ampliar as reflexões para enriquecer e aperfeiçoar a metodologia” (MEC, 2011c).

O referencial teórico que fundamenta o Guia não está declarado a priori, mas, conforme Veiga-Neto (2013, p. 10), pelos enunciados em que se alojam as palavras, ou seja, pelas redes discursivas, é possível apreender os seus sentidos. Dessa forma, pequenos trechos como "oferta de uma formação emancipatória e geradora de autonomia"; "desenvolver autonomia e exercer de forma plena sua cidadania"; entre outros, possibilitam compreender que a proposta está fundamentada na pedagogia progressista. Nesta perspectiva educativa,

[...] todos os sujeitos estão ativamente envolvidos no ato de conhecimento. $\mathrm{O}$ mundo, o objeto a ser conhecido, não é simplesmente comunicado; o ato pedagógico não consiste apenas em comunicar o mundo. Em vez disso, educador e educandos criam, dialogicamente, um conhecimento do mundo (SILVA, 2013b, p. 60).

A concepção de aprendizagem está fundamentada na abordagem construtivista; baseia-se no reconhecimento da experiência e dos conhecimentos pré-existentes trazidos pelas educandas. Utiliza-se, ainda, dos processos de aprendizagem significativa conforme descrito no quadro abaixo. 
Processos formativos na educação profissional: reflexões sobre o programa Mulheres Mil do IFSULDEMINAS

Quadro 1: $\quad$ Fundamentação teórico-metodológica

\begin{tabular}{|c|c|}
\hline FUNDAMENTAÇÃO & Teoria da aprendizagem significativa \\
\hline AUTORES REFERENCIADOS & David Ausubel e Cesar Coll \\
\hline CONCEPÇÃO DE APRENDIZAGEM & $\begin{array}{l}\text { Valorização do conhecimento prévio } \\
\text { trazido pela educanda; reconhecimento da } \\
\text { educanda como sujeito da aprendizagem; } \\
\text { a educanda aprende significativamente } \\
\text { quando é capaz de trazer o conhecimento } \\
\text { para sua realidade; reconhecimento de que } \\
\text { cada indivíduo traz consigo os saberes que } \\
\text { possuem sobre os conteúdos concretos que } \\
\text { se dispõem a aprender; os conteúdos são } \\
\text { baseados em situações da vida cotidiana, } \\
\text { de forma que o saber científico não seja } \\
\text { apenas verdadeiro, mas útil nas situações } \\
\text { da realidade. }\end{array}$ \\
\hline INSTRUMENTO & $\begin{array}{l}\text { Identificação de saberes baseado no } \\
\text { mapeamento dos conhecimentos } \\
\text { preliminares das educandas considerando- } \\
\text { se as aprendizagens formal }{ }^{11} \text {, não formal }{ }^{12} \\
\text { e informal }{ }^{13} \text {. }\end{array}$ \\
\hline ESTRATÉGIA & $\begin{array}{l}\text { Questionário }^{14} \\
\text { Entrevista }^{15} \\
\text { Mapa da Vida }^{16} \\
\text { Portfólio }^{17} \\
\text { Avaliação }^{18} \text { e autoavaliação }\end{array}$ \\
\hline
\end{tabular}

Fonte: MEC (2011c).

Um dos instrumentos utilizados para identificação dos conhecimentos prévios das educandas é denominado "Mapa da vida", o qual constitui uma espécie de cartografia, uma alegoria sobre "por onde andei" e "para onde pretendo/posso ir". Trata-se de uma ferramenta que objetiva criar oportunidades e ambientes para relatos e troca de experiências de vida das mulheres. O método pretende potencializar o sujeito como autor da história da sua vida, da de seu grupo, instituição ou comunidade, ou seja, as experiências podem ser narradas e registradas por suas protagonistas (MEC, 2011c).

De acordo com Larrosa (2011), ao aprender a dizer-se na temporalidade de uma história, ao narrar-se, a pessoa aprende a ter um passado e administrar um futuro; a saber o que lhe acontece; a fazer-se inteligível em sua própria história, dando a si uma origem ou um destino, uma trama, uma série de transformações controladas, um sentido.

\footnotetext{
${ }^{11}$ Programas e cursos de organizações educacionais reconhecidas.

${ }^{12}$ Aprendizado estruturado, não reconhecido por instituições.

${ }^{13}$ Aprendizagens adquiridas por meio de experiências de trabalho e vida.

${ }^{14}$ Realizado no momento da entrevista.

${ }^{15}$ Realizado no momento da entrevista.

${ }^{16}$ Realizado nas primeiras aulas.

${ }^{17}$ Construído ao longo do processo educativo.

${ }^{18}$ Construído ao longo do processo educativo.
} 
A construção do mapa da vida estimula pessoas a organizar sua própria história numa cronologia que possibilite que cada uma visualize e apresente sua trajetória global. Coloca o sujeito diante da perspectiva de fazer escolhas e selecionar o que quer contar e registrar, revelando os fatos marcantes, as rupturas e as pessoas significativas (MEC, 2011c, p. 13).

No relato das educadoras, o "Mapa da vida" desponta com essa função de fazer as mulheres pensarem sobre si mesmas, além de apresentar, ainda, uma função diagnóstica para identificar as dificuldades que as cursistas têm e delinear um direcionamento para o trabalho educativo.

O "Mapa da vida", que é uma dinâmica específica do programa, ele exige que se faça antes de começar as aulas e aí a gente tem um contato bem mais próximo dessas mulheres porque o "Mapa da vida" é uma dinâmica que faz elas retratarem para gente toda a história delas, as dificuldades, os problemas (Educadora 3).

No processo de pensar-se sujeito, protagonistas de suas próprias histórias, outra educadora expõe a surpresa das mulheres ao executar a atividade, pois estas relataram que nunca haviam tido tempo para pensar em planejar a própria vida.

\footnotetext{
Algumas delas relatavam: "Mas eu nunca parei para pensar, a gente não pensa nisso, vive a vida inteira sem pensar nisso, sem parar para pensar nessas questões" (Educadora 4).
}

Ao dialogar com as educandas sobre o exercício de pensar sobre suas histórias de vida, a educadora reafirma que

a ideia é mesmo a gente se permitir experenciar o novo, como por exemplo, pensar sobre questões que estão aí, parar para pensar é necessário em algum momento [...] parecia algo novo na vida de algumas, essa coisa [...] de pensar no amanhã, de pensar um projeto e de ter um tempo para pensar. Como se antes nunca tivesse sido possível sonhar, acreditar em alguma coisa (Educadora 4).

O excerto acima diz muito da história de vida das mulheres de Inconfidentes, pois, nas notas do trabalho de campo realizado no arquivo do programa, conforme a leitura de alguns documentos construídos ao longo da formação há relatos de mulheres que, apesar de desejarem estudar ou formar-se em alguma profissão, foram impedidas pelo pai e/ou pela mãe e, posteriormente, maridos. Assim, a perspectiva de retomar os estudos foi cada vez mais se aproximando de um sonho.

Contudo, o fato de terem dedicado grande parte da vida aos cuidados da família não anulou o desejo de sonhar com outras possibilidades de vida. A educadora relata, a seguir, a percepção que as mulheres vão construindo de si mesmas e de sua relação com os outros, com base na elaboração do seu "Mapa da vida". 
[...] [Há] uma tamanha necessidade de se reconhecer como sujeito para além da questão da família, de apontarem isso, de se surpreender e dividir com a gente a surpresa de que nunca haviam pensado em algumas questões ali, que aquela proposta simples de pensar como se era antes, como se é hoje, como se quer ser amanhã trazia para elas (Educadora 4).

O "Mapa da vida" diz respeito também aos compromissos coletivos,

[...] essa dinâmica que é feita num dos primeiros momentos tem mesmo essa função de estabelecer um vínculo, de fazer um enquadre com elas, de um compromisso no grupo, de respeito à história do outro, da sua própria história, questão de um compromisso com o que está sendo dito, está sendo falado pelo outro, por mais que para alguns do grupo possa ser uma coisa muito tranquila, para outros é muito difícil para aquela pessoa falar e expor de si (Educadora 4).

Gohn (2011, p. 114) entende que a voz ou vozes que entoam os participantes de processos educativos de educação não formal são carregadas de emoções, pensamentos e desejos. Ao se expressar, os/as atores/atrizes sujeitos dos processos de aprendizagem articulam o universo de saberes disponíveis, passado e presente, no esforço de pensar/elaborar/reelaborar sobre a realidade em que vivem. Tal percepção pode ser expressa da seguinte forma:

Então o respeito com a escuta, uma coisa que elas desenvolveram, aceitaramse e se sentiram seguras no vínculo com o trabalho com a gente muito a partir desse momento que a gente acolheu a possibilidade de elas pensarem o que elas foram, quem elas são, o que elas querem para a vida. Mas muito dentro desta perspectiva de que aquele grupo era um grupo de acolhimento, de vínculo, de compromisso, de se responsabilizar por si, mas também tinha uma costura de uma responsabilidade de um compromisso delas com a gente e com o papel que elas colocavam como projeto de vida para elas (Educadora 4).

Além disso, os processos de educação não formal expõem seu caráter baseado na prática social, nas relações/interações coletivas. Sendo assim, é a experiência das pessoas em trabalhos coletivos que gera um aprendizado e o conhecimento é adquirido por meio de situações problema. As ações interativas entre os indivíduos são fundamentais para a aquisição de novos saberes, e essas ações ocorrem fundamentalmente no plano da comunicação verbal, oral (GOHN, 2011).

De acordo com Silva (2011), posicionar o ator na construção do conhecimento sobre o passado permite que ele se torne, no presente, um agente de mudança, um agente movido por propósitos e intenções. Ao ser questionada sobre o porquê de as educandas se sentirem parte da proposta do Mulheres Mil, uma das educadoras expõe da seguinte forma: 
[...] o vínculo que elas puderam fazer com uma instituição que estava na comunidade, mas que não era acessível, não era para elas. Então o território nunca tinha sido antes aberto para elas, essa possibilidade, eu posso usar a biblioteca, mas eu posso transitar nesse território, nessa instituição que era a Escola Federal que tem na comunidade, mas que é enfim para os meninos que vem de fora, como elas dizem, para alguns cada vez mais próximos, mas para a juventude, para adolescentes e jovens (Educadora 4).

A percepção que a educadora traz no excerto acima tem a ver com a trajetória de vida das educandas que frequentaram o Mulheres Mil e suas relações com o hoje denominado IF, mas que, em diferentes tempos, foi escola - Escola Agrotécnica, Escola Agrícola, Patronato Agrícola -, enfim, espaço formativo historicamente negado às mulheres e que ganha importância na atualidade, mas cujo discurso de negação de acesso ainda (re)produz seus ecos.

No grupo de educandas selecionadas, há mulheres responsáveis pelo lar, donas de casa, ou seja, suas experiências de vida giram em torno da casa, da família e dos filhos, enfim, da vida privada. Essas mulheres cresceram no entorno do IF, olhando a instituição se expandir, porém, encarando-a como um espaço que não era para elas, como uma possibilidade perdida no tempo. Esse contexto remete à próxima narrativa em que a educadora apresenta a percepção das mulheres ao acessar a instituição:

[...] então essa mulher primeiro perder essa marca, que não é para ela aquele espaço, fazê-las acreditar nisso, muitas chegaram muito desconfiadas, mas como é, eu posso mesmo usar o refeitório, como é que eu posso marcar uma consulta [...] ter carteirinha, ser aluna do Instituto, usar o uniforme, isso deu uma identidade, enfim, eu acho que essa possibilidade desse vínculo, do acolhimento, do espaço de referência como um acolhimento eu acho que é um diferencial da proposta do Mulheres Mil neste sentido de as mulheres acreditarem que elas podem sim adentrar, fazer uso e serem regulamente matriculadas (Educadora 4).

A desconfiança da possibilidade do ingresso, o estranhamento de poder fazer uso do espaço, estabelece um confronto entre o dito construído historicamente, de que não poderiam fazer parte da instituição, e a atual proposta de possibilitar o acesso. O IF é reconhecido como um espaço privilegiado de formação e os seus estudantes têm uma identidade valorizada na comunidade; ao ocupar esse espaço, as mulheres desejam as mesmas possibilidades que são dadas aos demais estudantes. Essa sensação de pertencimento à instituição que as recebeu para uma formação possibilitou a desconstrução do espaço do IF como uma interdição e, ao mesmo tempo, um sentimento de valorização por fazer parte daquele lugar. Ademais, leva a pensar em quantas pessoas da comunidade e do entorno apresentam a mesma percepção que tiveram essas mulheres ao ingressar no programa. 
Conforme Bock, Furtado e Teixeira (2008), a apreensão do real é feita pelo sensível e reflexivo e, portanto, realizada pelo pensar, sentir, sonhar, imaginar. Desse modo, ao ilustrar suas próprias histórias com imagens, fotos trazidas de casa, desenhos, recortes de jornais e revistas, ao narrar suas trajetórias, as mulheres vão estabelecendo vínculos afetivos e constroem coletivamente um espaço de diálogo e de troca de conhecimentos.

Além do "Mapa da vida", foi adotada outra estratégia metodológica, o portfólio de aprendizagens. Nos processos educativos, o portfólio tem sido utilizado para registrar as atividades realizadas ao longo de um percurso formativo. De acordo com Shores (2001), ele contém anotações, rascunhos e esboços, amostras de trabalhos, diários de aprendizagens, sendo um processo que pode estimular questionamentos, proposições, análises e reflexões dos/as educandos/as.

No Mulheres Mil, os portfólios têm o propósito de congregar/registrar informações que demonstrem os conhecimentos, as habilidades e as competências desenvolvidas pelas educandas. Eles são orientados pelas seguintes questões:

Quadro 2: Questões reflexivas do portfólio

\begin{tabular}{|l|l|}
\hline Quem você é? & Descrever a experiência de vida e do trabalho. \\
\hline O que você faz? & Identificar o aprendizado obtido \\
\hline O que você aprendeu? & Relacionar aprendizado com a carreira \\
\hline Quais são seus objetivos? & Expressar o aprendizado, recolher provas \\
\hline
\end{tabular}

Fonte: 〈http://mulheresmil.mec.gov.br〉. Acesso em: 10 jan. 2014

A atividade realizada com os portfólios é vista como processo e produto, pois a partir dela se faz o atendimento, o acompanhamento e a avaliação dos conhecimentos e habilidades construídos durante a formação (MEC, 2011c). Constitui, dessa forma, um instrumento reflexivo em que são registrados os processos de aprendizagem de cada educanda e integra o processo avaliativo das mulheres.

Nos processos educativos, a avaliação da aprendizagem figura muitas vezes como "vilã", pelo fato de ter uma função punitiva e classificatória ou por expressar a condição de quem é retido/promovido. No caso do Mulheres Mil, por se tratar de um curso de formação inicial e continuada, que poderia envolver mulheres de diferentes escolaridades, cuja concepção educativa envolve o sujeito na construção de sua aprendizagem, a avaliação foi concebida como espaço formativo do qual a educanda faz parte. 
Do conjunto de estratégias "Mapa da vida", "Portfólio" e "Avaliação" são construídos os itinerários para que se realize o reconhecimento ${ }^{19}$ dos saberes das mulheres, pois os IF têm, dentre suas atribuições ${ }^{20}$, a possibilidade de reconhecer os saberes dos trabalhadores. Além disso, a equipe multidisciplinar ${ }^{21}$ de assessoramento do programa fica responsável por observar, analisar e registrar os avanços e eventuais dificuldades das educandas e coordena a discussão sobre a autoavaliação.

No Mulheres Mil, a certificação é possível pela elaboração de um plano educacional que leva em conta a realidade local. Além disso, há necessidade de identificação das lacunas de conhecimento dessas mulheres no que diz respeito a escolaridade, emprego e renda. Nesse caso, o IF não cumpre apenas a função de certificar, uma vez que existe um compromisso, caso as mulheres não possuam os conhecimentos necessários, de se promover cursos formativos para que elas possam adquirir os conhecimentos/habilidades que ainda não dominam.

É possível, no processo educativo das mulheres, discutir sobre as possibilidades de retorno à escola nos moldes de programas como o Brasil Alfabetizado ${ }^{22}$, ou como os outros programas que as secretarias municipais e estaduais de educação ofereçam e/ou no próprio IF em turmas vinculadas ao Programa Nacional de Integração da Educação Profissional com a Educação Básica na modalidade da Educação de Jovens e Adultos $\left(\operatorname{PROEJA}{ }^{23}\right)$.

Os cursos ofertados têm carga horária de 160 (cento e sessenta) horas, sendo oferecidos sob a forma de qualificação profissional, e o módulo educacional central apresenta as disciplinas obrigatórias a serem cursadas no programa. De acordo com o

19 De acordo com a Lei de Diretrizes e Bases da Educação Nacional (BRASIL, 1996, art. 41), “o conhecimento adquirido na educação profissional, inclusive no trabalho, poderá ser objeto de avaliação, reconhecimento e certificação para prosseguimento ou conclusão de estudos”.

20 A lei 11.892/2008 que criou os IF determina que as instituições da Rede Federal, no âmbito de sua atuação, exercerão o papel de instituições acreditadoras e certificadoras de competências profissionais adquiridas informalmente pelos/as trabalhadores/as em suas vivências (BRASIL, 2008).

21 Equipe multidisciplinar: Gerente do Projeto; Orientador Educacional/Pedagogo; Docentes das áreas do conhecimento exigidas para desenvolvimento do Programa; Assistente Social e Psicólogo; Médico e Odontólogo; Educadores técnico-administrativos; Comunicador; Educador que tenha domínio dos instrumentos de reconhecimento de aprendizagem prévia (CERTIFIC, ARAP, "Portfólios", "Mapas de vida" etc.).

22 Programa do Ministério da Educação (MEC) voltado para a alfabetização de jovens, adultos e idosos.

23 Programa que propõe a integração da educação profissional à educação básica na modalidade da Educação de Jovens e Adultos (EJA). Pode ser ofertado das seguintes formas: educação profissional técnica integrada ao ensino médio; educação profissional técnica concomitante ao ensino médio; formação inicial e continuada ou qualificação profissional integrada ao ensino fundamental; formação inicial e continuada ou qualificação profissional concomitante ao ensino fundamental; formação inicial e continuada ou qualificação profissional integrada ao ensino médio; formação inicial e continuada ou qualificação profissional concomitante ao ensino médio. 
Guia, "todas as disciplinas aplicam-se à realidade do cotidiano das alunas e oferecem aplicabilidade imediata em suas vidas, em suas casas e no trabalho" (MEC, 2011c, p. 21).

O módulo profissionalizante permitiu que o IF fizesse os ajustes necessários para possibilitar a qualificação específica das mulheres. A elaboração dos cursos de certificação tomou por base os cursos já ofertados pela instituição (informática e alimentos); o curso de costura, por sua vez, atendeu à demanda local, pois a cidade se situa em uma região de confecções; e o curso de cuidador de idosos se enquadra em um nicho ocupacional demandado pelo envelhecimento da população, mas que se encaixa em um segmento de práticas de cuidados historicamente ocupado por mulheres.

É importante ressaltar que o currículo do programa congrega um perfil de sujeito que se deseja formar, ação estreitamente vinculada ao projeto curricular. Aquilo que está inscrito no currículo não é apenas informação; a organização do conhecimento corporifica formas de agir, sentir, falar e ver o mundo e o eu (POPKEWITZ, 2011). Pode-se afirmar que o currículo está centralmente envolvido naquilo que somos, naquilo que nos tornamos, naquilo que nos tornaremos. O currículo produz; o currículo nos produz (SILVA, 2010).

Ao contrário do que ocorre com os projetos formativos da escola comum, o que se deseja evidenciar no programa socioeducativo Mulheres Mil são as questões vinculadas a gênero, saúde, educação e trabalho, campos em que o Estado intenta produzir efeitos de mudança. Portanto, a matriz curricular do programa apresenta, entre seus conteúdos obrigatórios, conexão com as políticas públicas pelas quais o programa é atravessado. Conforme a narrativa da próxima educadora:

[...] a gente recebeu o material que falava da proposta, das ementas das disciplinas para a gente trabalhar, [...] não são disciplinas comuns, convencionais, vamos dizer assim, elas tinham um nome diferenciado e, com isso, fazer a disciplina casar com a questão da habilidade que elas têm (Educadora 3).

De modo mais amplo, o nome diferenciado das disciplinas esteve vinculado aos temas de sustentabilidade, saúde e meio ambiente; desenvolvimento pessoal: autoestima e relações humanas; cidadania e direito das mulheres; inclusão digital; e geração de renda/empreendedorismo. 
Paraíso ajuda a pensar sobre as possibilidades contidas em um currículo:

Um currículo é um composto heterogêneo, constituído por saberes diversos e com capacidades variadas; por sentidos múltiplos e com inúmeras possibilidades. [...]. Um currículo, também, está sempre cheio de possibilidades de rompimento das linhas do ser; de contágios que podem nascer e se mover por caminhos insuspeitados; de construção de modos de vida que podem se desenvolver de formas particulares. Um currículo é um artefato com muitas possibilidades de diálogos com a vida; com diversas possibilidades de modos de vida, de povos e de seus desejos. É um artefato com um mundo a explorar (2009, p. 278).

A autora traz à tona a possibilidade de o currículo dialogar com a vida; ou seja, apesar de conter prescrições, ainda assim, é possível "criar" no interior de um currículo, pois o fazer dos/as educadores/as não é limitado por uma rigidez, possibilitando que se posicionem quanto aos modos de fazer:

[...] nós tivemos disciplinas relacionadas à área de desenvolvimento humano, saúde da mulher [...] formação básica, [...] formação de texto, tivemos também matemática, então nós fomos ajustando o programa e fazendo com que essas disciplinas pudessem ser ministradas pelos professores, que eles entendessem e que as mulheres entendessem (Educadora 1).

Este excerto da entrevista permite pensar nas relações estabelecidas no âmbito das práticas pedagógicas do programa. De acordo com Silva (2013b), o currículo constitui também uma questão de poder: selecionar é uma operação de poder; privilegiar um tipo de conhecimento é uma operação de poder; destacar, entre as múltiplas possibilidades, uma identidade ou subjetividade como sendo ideal é uma operação de poder.

Como qualquer outro artefato cultural, o currículo nos constrói como sujeitos particulares, específicos. Não é meramente uma operação cognitiva em que certos conhecimentos são transmitidos a sujeitos dados e formados de antemão. Tão pouco pode ser entendido como uma operação destinada a extrair, a fazer emergir uma essência humana que preexista à linguagem, ao discurso e à cultura. O currículo pode ser visto como um discurso que, ao corporificar narrativas particulares sobre o indivíduo e a sociedade, constitui-nos como sujeitos. Pode-se dizer que o currículo não está envolvido num processo de transmissão ou de revelação, mas num processo de constituição e posicionamento: de constituição do indivíduo como um sujeito de determinado tipo (SILVA, 2013a, p. 189-190).

O currículo é a construção de nós mesmos como sujeitos (SILVA, 2013a) e, muito embora se esteja discutindo o currículo de um programa governamental, pode-se dizer que ele também é atravessado pelas relações de poder. Trata-se de relações que definiram, entre outras coisas, a construção do texto que fundamenta o programa, o perfil das mulheres selecionadas, bem como o direcionamento do trabalho dos educadores.

Por outro lado, o fato de ser um programa de cunho social pode ter contribuído/favorecido a constituição de relações mais flexíveis na sala de aula, uma vez 
que não há um modo de ensinar pré-determinado nem um currículo formal e/ou uma receita instituída. O sujeito autorizado a falar em sala de aula não teria, necessariamente, de ser o/a educador/a, pois a concepção do programa se fundamenta na participação das mulheres.

[...] o meu trabalho com elas, como educadora, tinha muito essa perspectiva de que elas pudessem fazer perguntas e produzir as próprias respostas, que saísse do grupo, que o grupo pudesse ser autogestivo neste sentido e foi assim muito bacana para mim esse contato e perceber o movimento de como todo grupo se organiza, que tem seu tempo e o seu movimento [...] eu atuei nos quatro cursos percebi esse movimento comparativo (Educadora 4).

Este posicionamento da educadora, na condução do seu trabalho em sala de aula, conduziu-me a Gallo (2000). De acordo com o autor:

\begin{abstract}
A formação do aluno jamais acontecerá pela assimilação de discursos, mas sim por um processo microssocial em que ele é levado a assumir posturas de liberdade, respeito, responsabilidade, ao mesmo tempo em que percebe essas mesmas práticas nos demais membros que participam deste microcosmo com que se relaciona no cotidiano. Uma aula de qualquer disciplina constitui-se em parte do processo de formação do aluno, não pelo discurso que o professor possa fazer, mas pelo posicionamento que assume em seu relacionamento com os alunos, pela participação que suscita neles, pelas novas posturas que eles são chamados a assumir (GALLO, 2000, p. 20).
\end{abstract}

Nesse sentido, a forma como a proposta do Mulheres Mil foi construída cria possibilidades para que esses tipos de relações se efetivem em sala de aula, uma vez que sua proposta educativa pressupõe o envolvimento das educandas para que o currículo possa ganhar vida.

Ao falar do currículo "vivo", uma das educadoras explicita que, apesar dos documentos norteadores, a dinâmica em sala de aula dependia muito do que as mulheres traziam e que elas transitavam no projeto segundo suas experiências. Quando questionada sobre como foram abordadas as questões relativas ao gênero e à violência, a educadora menciona que não existia uma delimitação exata por conteúdo:

[...] a gente tentou perpassar essas questões, em várias unidades de estudos, a gente falou da questão da saúde da mulher, então tinha lá a educadora que trazia essa discussão, mas aparecia lá numa outra disciplina num outro momento com outra educadora que estava se propondo a falar de direito da mulher, aparecia comigo que falava de relação e desenvolvimento interpessoal, então era interessante porque estas questões do mundo, do universo de vivências e experiências perpassava, elas não ficavam nessas caixinhas e elas conseguiam fazer muito bem esses atravessamentos e traziam questões de saúde da mulher para discutir comigo, que trabalhava outras questões mais objetivas, assim como o direito da mulher, então a gente via que elas conseguiam fazer esse trânsito, propunham estas questões para além desse modelo que a gente tem que agora a gente vai discutir isso, eu acho que essa metodologia também de partir da necessidade, da demanda da fala delas possibilitou que não ficasse nessas caixinhas e pudesse realmente ouvi-las e ver quais eram as questões (Educadora 4). 
É importante destacar que o combate à violência contra a mulher constitui uma das ações prioritárias da Secretaria Nacional de Políticas para Mulheres. Nesse caso, a difusão do conhecimento sobre a legislação cria possibilidades de as vítimas compreenderem e identificarem aquilo que pode ser tomado como violência(s) e as possibilidades de se defender.

\begin{abstract}
As violências praticadas contra as mulheres devido ao seu sexo assumem múltiplas formas. Elas englobam todos os atos que, por meio de ameaça, coação ou força, lhes infligem, na vida privada ou pública, sofrimentos físicos, sexuais ou psicológicos com a finalidade de intimidá-las, puni-las, humilhálas, atingi-las em sua integridade física e na sua subjetividade (HIRATA et al., 2009, p. 271).
\end{abstract}

$\mathrm{O}$ fato de haver um curso destinado especificamente para mulheres criou possibilidades de elas perguntarem, tirarem dúvidas. Portanto, o espaço formativo do curso pode ser visto como uma conquista, uma vez que, se estivessem em espaços de usos coletivos, voltariam para casa sem fazer as perguntas que gostariam.

Além disso, a metodologia do programa criou possibilidades para que a mulher por ele contemplada se dissesse vítima de violência quando fosse o caso, para que trouxesse seus questionamentos quanto à saúde, à sexualidade, e ainda para que pudesse discutir sobre a informalidade de seu trabalho e sobre as possibilidades de seu retorno à escola. Esses momentos de reflexão, possibilitados pelo Mulheres Mil, apontam para a importância de os sujeitos se sentirem parte de uma proposta, a fim de que criem sentidos de aprendizagem para além dos conteúdos ministrados.

\title{
Considerações finais
}

O Mulheres Mil não resolve problemas históricos relacionados às questões de gênero, saúde, educação e trabalho, mas avança no tocante a uma metodologia e a uma sensibilização das mulheres para um "algo mais". Porém, para que elas possam dar prosseguimento aos estudos e ao trabalho, por exemplo, é necessário que outras condições lhes sejam asseguradas, quer para aquelas que não têm onde deixar os filhos, quer para aquelas vinculadas às práticas de cuidado e da casa.

A metodologia do Mulheres Mil mostrou-se importante para o desenvolvimento do programa, para a motivação e o sentimento de pertencimento em relação ao IF. Contudo, é necessário discutir a forma como esse acesso foi realizado, pois, apesar de o programa possibilitar às mulheres se reconhecerem e se identificarem como alunas da instituição, estes processos ocorrem dentro de uma excepcionalidade, em um programa

Olh@res, Guarulhos, v. 4, n. 1, p. 161-181, maio 2016. 
especial. Portanto ainda cabe, às políticas públicas e ao IF, pensar nas possibilidades de acesso pleno das mulheres aos seus cursos técnicos e superiores.

No tocante à proposta educativa e ao relato das educadoras com base em suas percepções a respeito do programa, notei, pelos dados de pesquisa, que, apesar da urgência com que o programa chega à rede federal e, até mesmo, à forma como as mulheres foram selecionadas, até o seu ingresso na sala de aula, ele ainda se constituiu um desafio para todos/as aqueles/as que se dispuseram a participar.

Apesar de o IF estar credenciado para ministrar atividades educativas que vão da educação básica à educação superior, o público usual da instituição, mesmo sendo diversificado, não apresenta um perfil que se aproxime do encontrado no Mulheres Mil. No programa havia educandas com idades e escolaridades variadas, assim, para os/as educadores/as que se dispuseram a vivenciar aquele desafio, não havia outra possibilidade que não a de utilizar as estratégias metodológicas do programa, pois a realidade trazida pelas mulheres indicava que transpor a metodologia da sala de aula comum para o Mulheres Mil não funcionaria e os/as educadores/as aceitaram lidar com essas dificuldades.

\section{REFERÊNCIAS BIBLIOGRÁFICAS}

BOCK, A. M. B.; FURTADO, O.; TEIXEIRA, M. de L. T. Psicologias: uma introdução ao estudo da psicologia. 14. ed. São Paulo: Saraiva, 2008. 368 p.

BRAGA, A. C. F. Projeto mulheres mil e gênero: comercialização das pequenas produções das mulheres no setor Santa Bárbara em Palmas, TO. 2011. 77 f. Dissertação (Mestrado em Educação Agrícola) - Universidade Federal Rural do Rio de Janeiro, Rio de Janeiro, 2011.

BRASIL. Lei no 11.892, de 28 de dezembro de 2008. Institui a Rede Federal de Educação Profissional, Científica e Tecnológica, cria os Institutos Federais de Educação, Ciência e Tecnologia, e dá outras providências. Brasília, 2008. Disponível em: <http://www.planalto.gov.br/ccivil_03/_ato2007-2010/2008/lei/111892.htm>. Acesso em: 8 dez. 2013.

BRASIL. Lei no 9.394, de 20 de dezembro de 1996. Estabelece as Diretrizes e Bases da Educação Nacional. Brasília, 1996.

GALLO, S. Conhecimento, transversalidade e currículo. In: ALVES, N.; GARCIA, R. L. (Org.). O sentido da escola. Rio de Janeiro: DP\&A, 2000. p. 17-41. 
GOHN, M. da G. Educação não formal e cultura política: impactos sobre o associativismo do terceiro setor. 5. ed. São Paulo: Cortez, 2011. 128 p.

HIRATA, H. et al. (Org.). Dicionário crítico do feminismo. São Paulo: UNESP, 2009. $344 \mathrm{p}$.

INSTITUTO FEDERAL DE EDUCAÇÃO CIÊNCIA E TECNOLOGIA DO SUL DE MINAS GERAIS. Projeto pedagógico de capacitação técnica do programa mulheres mil. Inconfidentes, 2012.

LAGOS, M.B. Palmas para mulheres mil em comunidades Quilombolas: a participação do IFPR, Campus Palmas, no programa nacional de inclusão social. Dissertação (Mestrado em Desenvolvimento Regional). 2014. 140f. Universidade Tecnológica do Paraná, Pato Branco, 2014.

LARROSA, J. Tecnologias do eu e educação. In: SILVA, T. T. da (Org.). O sujeito da educação: estudos foucaultianos. 8. ed. Petrópolis: Vozes, 2011. p. 35-86.

MACHADO, L. R. de S. Saberes profissionais nos planos de desenvolvimento de institutos federais de educação. Cadernos de Pesquisa, São Paulo, v. 41, n. 43, maio/ago. 2011. Disponível em: <http://www.scielo.br/scielo.php?script=sci_arttext\&pid=S010015742011000200003\&lng=en\&nrm=iso >. Acesso em: 31 jul. 2014.

MEC - Ministério da Educação. Portaria no 1.015, de 21 de julho de 2011. Institui o Programa Nacional Mulheres Mil. Brasília, 2011a.

MEC - Ministério da Educação. Programa Mulheres Mil. Brasília, 2011b. Disponível em: <http://mulheresmil.mec.gov.br/>. Acesso em: 9 dez. 2013.

MEC - Ministério da Educação. Guia metodológico do Programa Nacional Mulheres Mil: Educação, cidadania e desenvolvimento sustentável. Brasília, 2011c. 42 p.

OLIVEIRA, M. A. S. M. Programa mulheres mil no Instituto Federal de Sergipe: interfaces com a educação e o trabalho. 2013. 157 f. Dissertação (Mestrado em Serviço Social) - Universidade Federal de Sergipe, São Cristóvão, 2013.

PACHECO, E. Institutos Federais: um futuro em aberto. Prefácio. In: SOUZA, E. C. L. de; CASTIONI, R. (Org.). Institutos Federais: os desafios da institucionalização. Brasília: UnB, 2012. p. 7-11.

PARAÍSO, M. A. Currículo, desejo e experiência. Educação e Realidade, Porto Alegre, v. 34, n. 2, p. 277-293, maio/ago. 2009.

PEREIRA, J.S.A. Programa Mulheres Mil: uma análise no campo das políticas de inclusão. 2015. 171f. Dissertação (Mestrado em Educação). Universidade Federal de Santa Catarina, Florianópolis, 2015. 
POPKEWITZ, T. S. História do currículo, regulação social e poder. In: SILVA, T. T. da (Org.). O sujeito da educação: estudos foucaultianos. 8. ed. Petrópolis: Vozes, 2011. p. 173-210.

RIBEIRO, L.E.G. A qualificação profissional e cidadã: um estudo do programa Mulheres Mil, a partir da experiência do Instituto Federal de Goiás, Campus Luziânia. 2013. 155f. Dissertação (Mestrado em Educação) - Universidade de Brasília, Brasília, 2013.

ROSA, Stela (org.). Mulheres Mil na rede federal: Caminhos da inclusão. Brasília: MEC, 2011a. 168 p.

ROSA, Stela (org.). Mulheres Mil: Do sonho à realidade. Brasília: MEC, 2011b. 422p.

SHORES, E. F; GRACE, C. Manual de portfólio: um guia passo a passo para o professor. Porto Alegre: Artmed, 2001. 160 p.

SILVA, T. T. da. O currículo como fetiche: a poética e a política do texto curricular. Belo Horizonte: Autêntica, 2010. 120 p.

SILVA, T. T. da. Currículo e identidade social: territórios contestados. In:

Alienígenas na sala de aula: uma introdução aos estudos culturais em educação. 11. ed. Petrópolis: Vozes, 2013a. p. 185-201.

SILVA, T. T. da. Documentos de identidade: uma introdução às teorias do currículo. 3. ed. Belo Horizonte: Autêntica, 2013b. 156 p.

SILVA, T. T. da (Org.). O sujeito da educação: estudos foucaultianos. 8. ed. Petrópolis: Vozes, 2011. 264 p.

VEIGA-NETO, A. Apresentação - Minimae parabolae. In: FABRIS, E. T. H.; KLEIN, R. R. (Org.). Inclusão e biopolítica. Belo Horizonte: Autêntica, 2013. p. 7-13.

Recebido em: 14/02/2016

Aprovado em: 28/04/16 